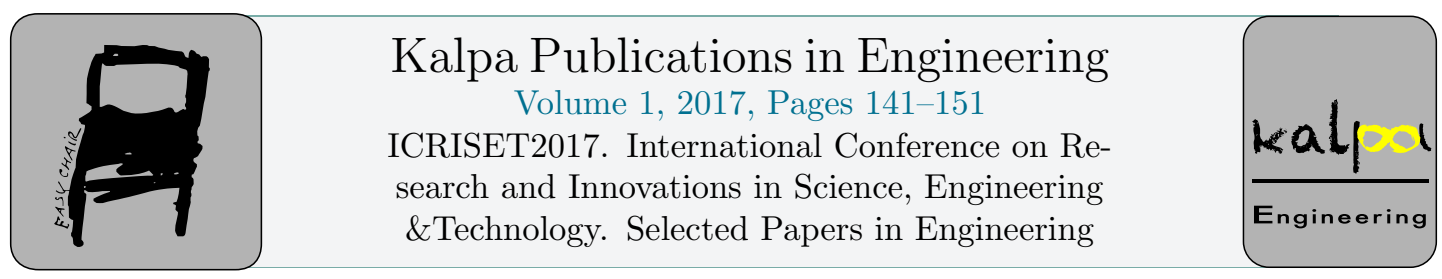

\title{
Development of Functionally Graded Metal Composite (LM25-SiC) Using Centrifugal Casting Process and their Characterisation
}

\author{
Kinjal Patel ${ }^{1,4}$, Viral Panara ${ }^{2,5}$ and Dr. Mayur Sutaria ${ }^{3,5}$ \\ ${ }^{1}$ Assistant Prof., ${ }^{2}$ Assistant Prof., ${ }^{3}$ Professor. \\ ${ }^{4}$ Mech. Engg. Dept., BVM Engineering College, V.V.Nagar, Gujarat, India. \\ ${ }^{5}$ Mech. Engg. Dept., CSPIT, CHARUSAT, Changa, Gujarat, India. \\ kinjal_patel93@yahoo.com, viralpanara.medcharusat.ac.in \\ mayursutaria.me@charusat.ac.in
}

\begin{abstract}
The research work includes development of vertical centrifugal casting set-up for functionally graded metal composite (LM25-SiC) preparation. Material parameters like wt \% of SiC Particles (2, 3.5, and 5\%), average grain size of $\mathrm{SiC}$ particles $(75,44$, and $6.5 \mu \mathrm{m})$ and process parameter like rotational speed of the mould $(1000,1100,1200$ RPM) are selected for characterization. Samples were tested for hardness and wear resistance to investigate the effect parameters on change of properties. Microstructure analysis was also performed. Total 11 FGM samples were made by varying different process parameters. It is found that hardness and wear resistant property improves with increase in $\mathrm{wt} \%$ of $\mathrm{SiC}$ particles and mould rotation speed. It is also found that hardness and wear resistance value increases with reduction of average grain size of $\mathrm{SiC}$ particles. Increased mould rotation speed improves the level of distribution of reinforcing particles from inner to outer region.
\end{abstract}

\section{Introduction}

There are certain applications of composite materials where it does not perform desirably in certain extreme conditions and material gets fail. This can happen for example, in high temperature application, where two metals with different coefficient of expansion are used. Functionally graded material is motivated by the need for properties, which are unavailable in single material.

Functionally graded composite material exhibits a continuous variation of material properties, which results from non-homogeneous microstructure. FGMs possess a position dependent microstructure, chemical composition or atomic order, which may result in continuous variation of material properties 
with position. Japanese scholars first proposed the concept of functionally gradient materials to address conventional heat-resistant materials under extreme conditions and inadequacies [1]. FGMs are classified based on its structure and method of manufacturing. Continuous gradation and stepwise gradation are based on its structure, thin FGMs and bulk FGMs are based on method of manufacturing [2].Various fabrication techniques have been reported to prepare FGM [3]. Among all fabrication method, centrifugal casting is widely used in industries to develop axisymmetric bulk FGM with continuous gradation. The principal advantage of this method is to have proper mould filling with good microstructural control and excellent mechanical properties $[4,5]$.

FGM from various combinations of base metal and reinforcing particles have been reported like Al$\mathrm{SiC}, \mathrm{Al}-\mathrm{Al}_{2} \mathrm{O}_{3}$, and $\mathrm{Al}-\mathrm{TiO}_{2}$ etc for different applications [6]. Al-SiC FGM provides excellent combination of properties like high strength to weight ratio, good corrosion/wear resistant property, thermal stability, increased hardness at outer region which is very useful in applications like furnace wall, rocket nozzle, tool inserts etc. FGM processing includes mechanical stirring of LM25 \& SiC particles followed by pouring of melt into rotating mould fitted in vertical centrifugal casting machine [7]. The present research work is on characterization of LM25- SiC FGMs, which includes hardness, wear resistance property measurement and microstructure analysis [8].

\section{Material and Process Parameters}

\subsection{Material Selection}

Vertical centrifugal casting apparatus was designed and fabricated to develop FGM components of required size and properties. The set-up is shown in Figure 1. LM25 (Al-356) an aluminium alloy was selected as a base material. The chemical composition of LM25 is shown in Table 1. It has proven as a potential matrix alloy in the fabrication of cast aluminium matrix composites. SiC particles with average grain size of 75,44 and $6.5 \mu \mathrm{m}$ were selected as reinforcing particles on the basis of its easy availability. This combination provides an excellent set of mechanical properties. Also, SiC particles are known for its good mechanical properties, wear resistance property, high temperature strength and thermal shock resistance.

\begin{tabular}{|c|c|c|c|c|c|c|}
\hline $\begin{array}{c}\text { Aluminium } \\
\text { Association } \\
\text { Grade }\end{array}$ & $\begin{array}{c}\mathrm{Si} \\
\text { wt.\% }\end{array}$ & $\begin{array}{c}\mathrm{Mg} \\
\text { wt.\% }\end{array}$ & $\begin{array}{c}\mathrm{Cu} \\
\text { wt.\% }\end{array}$ & $\begin{array}{c}\mathrm{Fe} \\
\text { wt.\% }\end{array}$ & $\begin{array}{c}\text { Zn } \\
\text { wt.\% }\end{array}$ & $\begin{array}{c}\mathrm{Al} \\
\text { wt.\% }\end{array}$ \\
\hline LM25 & 7 & 0.35 & 0.2 & 0.2 & 0.1 & Balance \\
\hline
\end{tabular}

Table 1: Chemical composition of an Aluminium alloy (LM25)

\subsection{Process Parameters}

1. Material parameters: $\mathrm{Wt} \%$ of $\mathrm{SiC}$ particles $(2,3.5, \& 5 \%)$, Average grain size of $\mathrm{SiC}$ particles $(75,44, \& 6.5 \mu \mathrm{m})$

2. Process parameter: Mould rotation speed (1000, 1100, \&1200 RPM) 


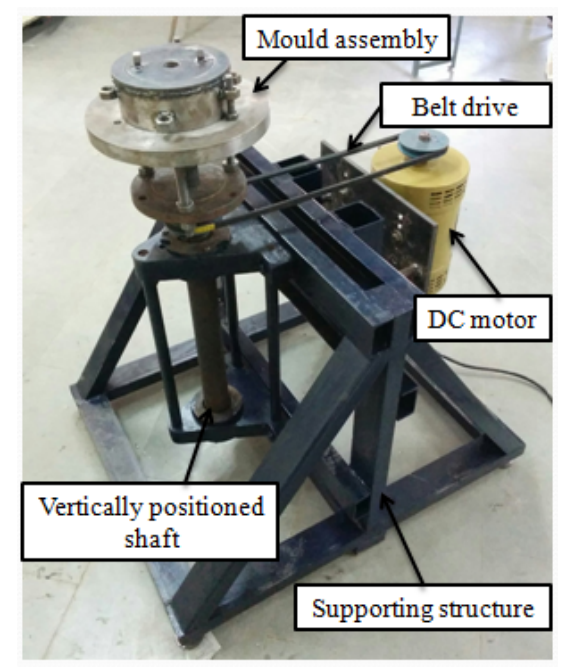

Figure 1: Vertical centrifugal casting set-up

\section{Experimental work}

\subsection{Melting of raw material and pre-heating of reinforcing particles ( $\mathrm{SiC})$}

Resistance heating furnace of $12 \mathrm{KW}$ power was used for melting of raw material, capable to withstand temperature up to $1100{ }^{\circ} \mathrm{C}$. Graphite crucibles were used for melting of LM-25. Resistance heating furnace having the provision to connect the stirrer mechanism. Preheating of silicon carbide particles makes the surface clean and enhances melt particle interaction. It removes absorbed surface contamination and raises the surface energy of solid thereby improving wettability of melt. SiC particles were preheated at a temperature of $800{ }^{\circ} \mathrm{C}$ for $3 \mathrm{hrs}$ in resistance heating furnace.

\subsection{Mixing of LM25 and reinforcing particles}

After complete melting of LM25, the crucible was taken outside from the furnace and degassing procedure was carried out to remove dissolved gases from the melt. 5 gram of dihydro-chloro-fluroethane powder was used as a degassing powder. 1\% of magnesium alloy powder was added in LM 25 melt in order to improve wettability of the melt.

FGM samples were prepared by adding pre-heated SiC particles into melted LM25 by manual stirring as well as mechanical stirring. The position of the stirrer inside the melt was always kept constant at the given level. The furnace have lifting device for controlling the position of the crucible bed. After that the preheated silicon carbide particles of selected were added manually in two stages. In first stage, half of the particles were added in semi-solid state and mixed by manual stirring. Manual stirring process continued till it become hard to stir it further. Then radial blade stirrer (vertical blade) took the crucible with semi solid slurry back to the furnace where it remelted and stirred mechanically at a speed of $450 \mathrm{rpm}$ for 5 minutes. The temperature of the melt slurry was maintained at $750{ }^{\circ} \mathrm{C}$. Same procedure was followed for addition of remaining half particles. A digital tachometer was used to 
measure the stirring speed. Another crucible was pre heated $\left(\right.$ at $500{ }^{\circ} \mathrm{C}$ ) for transferring the melt of required quantity.

Meanwhile, mould pre-heating was carried out on induction cooktop at $240{ }^{\circ} \mathrm{C}$ for 30 minutes to ease the flow and for reduced thermal damage to the casting. After Pre heating of mould uniform layer of die coat was applied for easy removal of casted piece from mould. After that pre- heated mould was positioned on the base plate of the centrifugal casting set up. The mould was lifted and positioned with the help of iron rods as shown in Figure 2(a) and 2(b).

For having FGM samples of uniform dimensions (ID $=55 \mathrm{~mm}, \mathrm{OD}=115 \mathrm{~mm}, \mathrm{H}=40 \mathrm{~mm}$ ), required quantity of melt $(855 \mathrm{gm})$ was taken into pre-heated crucible. It was measured by digital weighing machine having accuracy of $0.001 \mathrm{gm}$ as shown in Figure 2(c). The pouring system with funnel was also set exactly above the center of mould upper plate. Meanwhile pouring temperature of melt was measured using dip tip type thermometer as shown in Figure 2(d). Pouring temperature was $750-760^{\circ} \mathrm{C}$ for all FGM sample. Funnel was positioned above mould and required position was achieved by adjustable $\mathrm{C}$ shape frame in $\mathrm{X}$ and $\mathrm{Y}$ direction as shown in Figure 2(e).

After starting the machine once the required RPM reach, the weighed quantity of prepared melt was directly poured into rotating mould as shown in Figure 2(f) and 2(g). It took 7-8 seconds for pouring the melt into the rotating mould. Mould was allowed to rotate for 1.5 minutes.

After that mould was lifted up from its position on the base plate and continuous water supply has been applied for 1 minute. After the forced cooling process FGM component has been removed from the mould using tongs as is shown in Figure 3.

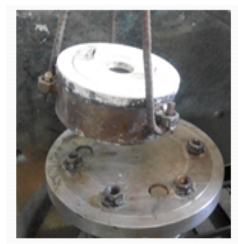

A.Positioning of Mould

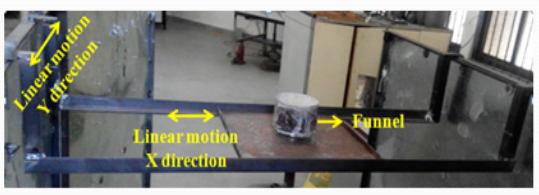

E .Funnel positioning

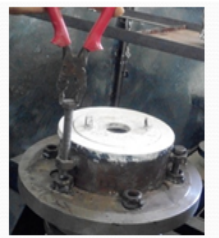

B. Fixing of Mould

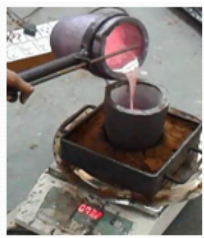

C. Weighing of Melt

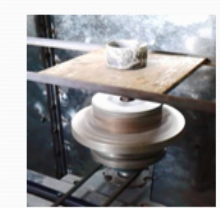

F .Mould rotation

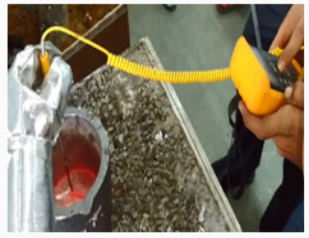

D. Pouring Temp. measurement

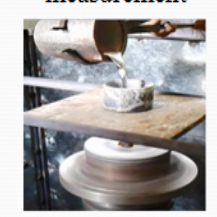

G. Pouring of melt

Figure 2: Mould fixing and pouring process

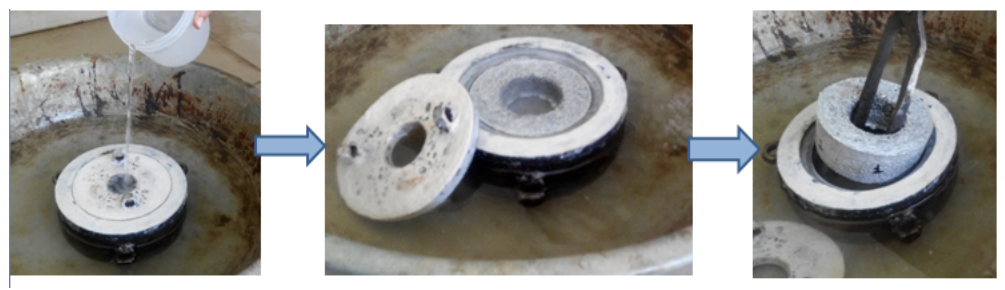

Figure 3: Cooling and removal process 


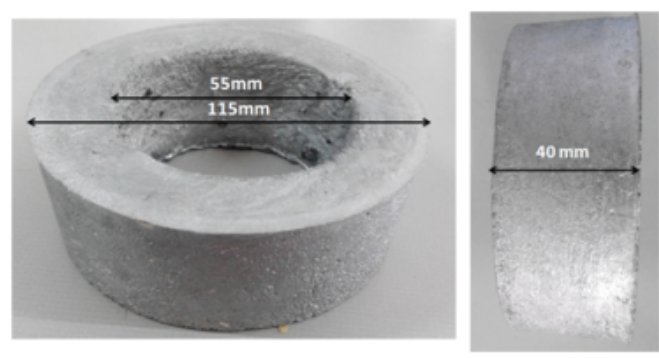

Figure 4: Dimension of FGM sample

\begin{tabular}{|c|c|c|c|}
\hline $\begin{array}{c}\text { Sample } \\
\text { no. }\end{array}$ & $\begin{array}{c}\text { Grain size of } \\
\mathrm{SiC} \\
\text { particles }(\mu \mathrm{m})\end{array}$ & $\begin{array}{c}\text { Rotational speed } \\
\text { of } \\
\text { mould(RPM) }\end{array}$ & $\begin{array}{c}\text { Wt \% of SiC } \\
\text { particles }\end{array}$ \\
\hline 1. & 75 & 1000 & 2 \\
\hline 2. & 75 & 1000 & 3.5 \\
\hline 3. & 75 & 1000 & 5 \\
\hline 4. & 75 & 1100 & 3.5 \\
\hline 5. & 75 & 1100 & 5 \\
\hline 6. & 75 & 1100 & 2 \\
\hline 7. & 75 & 1200 & 5 \\
\hline 8. & 75 & 1200 & 2 \\
\hline 9. & 75 & 1200 & 2 \\
\hline 10. & 44 & 1200 & 5.5 \\
\hline 11. & 6.5 & 1200 & \\
\hline
\end{tabular}

Table 2: Specified combinations for FGM

Using the described procedure, total 9 FGM components were prepared with specified combinations of parameters as shown in Table 2. The combinations were taken to analyze the effect and relationship among process parameters and the affected Properties (Hardness, Wear).

Figure 4. Shows the dimension of prepared FGM component. Inner diameter of 55mm, outer diameter of $115 \mathrm{~mm}$ and height of $40 \mathrm{~mm}$.

\section{Characterization}

FGM sample characterization includes optical microstructure analysis, hardness analysis and wears rate analysis.

\subsection{Microstructure Test}

Sample for microstructure testing is shown in Figure 5. Double disc variable speed grinding/lapping machine was used for preparing the sample for microstructure analysis using optical microscope, images were captured at 200X resolution. 


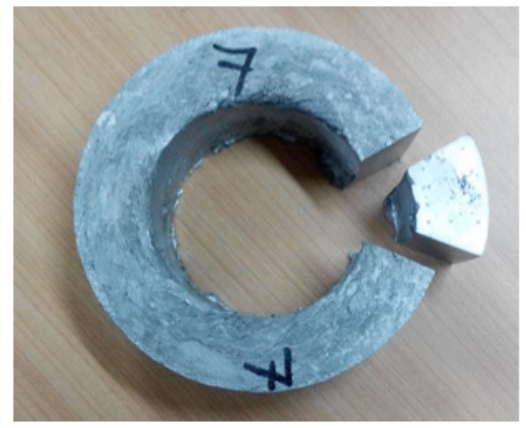

(a)

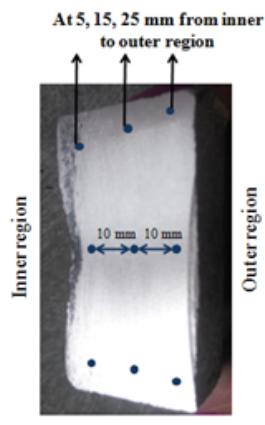

(b)

Figure 5: Sample for microstructure analysis

The optical microstructure of unetched FGM sample at inner, intermediate and outer regions for sample with $\mathrm{SiC}$ particles of $75 \mu \mathrm{m}$ is shown in Figure 6. It can be observed from the images that outer region is the particle rich zone as more numbers of $\mathrm{SiC}$ particles are observed and inner region is the matrix rich zone as few numbers of $\mathrm{SiC}$ particles are observed. Improved particles distribution is observed with increase in radial distance.

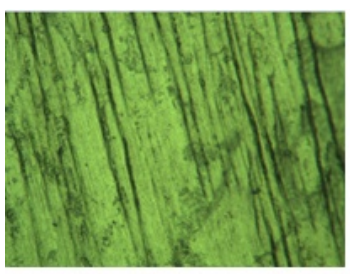

(a)

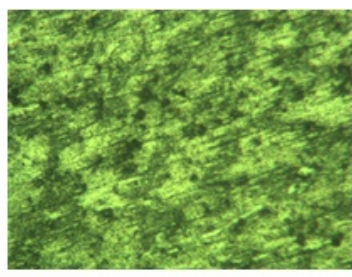

(b)

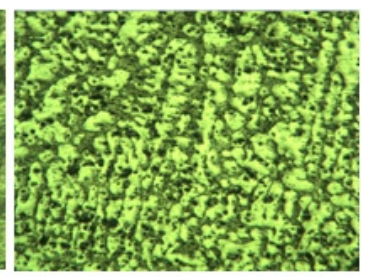

(c)

Figure 6: Microstructures at (a) Inner region, (b) Intermediate region, (c) Outer region for FGM sample (1200RPM, 5\% SiC, 75 micron)

\subsection{Hardness Test}

Rockwell hardness apparatus (1/16" Steel ball, $100 \mathrm{Kgs}$ load) was used for hardness measurement as shown in Figure 7(a). The test has been performed in accordance with ASTM E8-12. Testing sites were located in inner layer $(5 \mathrm{~mm})$, intermediate layer $(15 \mathrm{~mm})$ and outer layer $(25 \mathrm{~mm})$. Readings were taken at four positions in these layers for all samples as shown in Figure 7(b). The average value was taken as a final reading.

Trend of hardness variation with $\mathrm{wt} \%(2,3.5$, and 5$)$ of $\mathrm{SiC}$ particles and mould rotation speed is shown in Figure 8 and 9 respectively. Hardness value increases with increase in amount of $\mathrm{SiC}$ particles. Maximum hardness is achieved for sample containing $5 \%$ of $\mathrm{SiC}$ particles as shown in Figure 8. Hardness value also increases with increase in mould rotation speed. Maximum hardness is achieved for 1200 RPM as shown in Figure 9. It can be observed that hardness value increases from inner region to outer region as more number of $\mathrm{SiC}$ particles are pushed at outer region of FGM due to higher density which is validation of particle Rich region at outer periphery of the FGM samples. The average measured hardness value (HRB) at 5, 15 and $25 \mathrm{~mm}$ is shown in Table 3. 


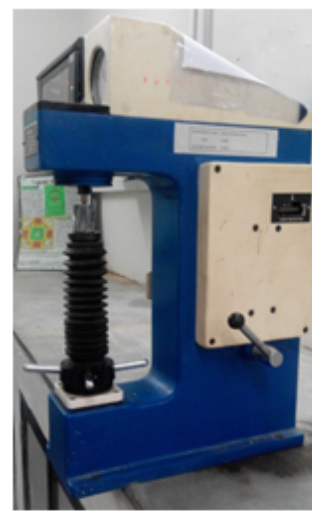

(a)

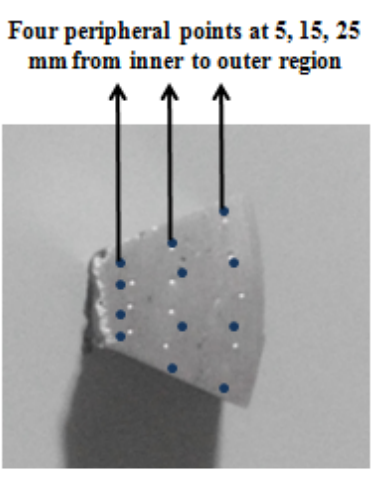

(b)

Figure 7: (a) Rockwell hardness tester, (b) sample for hardness measurement

It can be observed that hardness value increases from inner region to outer region as more number of SiC particles are pushed at outer region of FGM due to higher density which is validation of particle Rich region at outer periphery of the FGM samples. The average measured hardness value (HRB) at 5,15 and $25 \mathrm{~mm}$ is shown in Table 3 .

\begin{tabular}{|c|c|c|c|}
\hline \multirow{2}{*}{ Hardness result } & \multicolumn{3}{|c|}{ Average value of hardness(HRB) } \\
\cline { 1 - 3 } $\begin{array}{c}\text { Radial distance } \\
\text { (inner to outer) }\end{array}$ & $5 \mathrm{~mm}$ & $15 \mathrm{~mm}$ & $25 \mathrm{~mm}$ \\
\cline { 1 - 3 } Sample No. & & & \\
\hline 1 & 32.5 & 37.25 & 40 \\
\hline 2 & 33 & 38.5 & 42.25 \\
\hline 3 & 34.5 & 39.75 & 44 \\
\hline 4 & 31.25 & 34.25 & 41.25 \\
\hline 5 & 32 & 39 & 43.5 \\
\hline 6 & 33.25 & 39.25 & 45 \\
\hline 7 & 29.25 & 35.75 & 43 \\
\hline 8 & 31.5 & 33.5 & 44.5 \\
\hline 9 & 32 & 40 & 46 \\
\hline
\end{tabular}

Table 3: Measured hardness (HRB) value for FGM samples

\subsection{Wear Test}

Wear test in accordance with ASTM G 99 standard was conducted for prepared FGMs using pinon-disc type wear and friction monitor apparatus with samples of cross section size $(10 \mathrm{~mm} * 10 \mathrm{~mm})$ and length of $30 \mathrm{~mm}$ shown in Figure 10. Each wear test has been carried out under the fix normal load of $2 \mathrm{~kg}$, track diameter of $60 \mathrm{~mm}$, the speed of $500 \mathrm{rpm}$ and time period of 10 minutes $[9,10]$.

Wear rate $(\mathrm{mg} / \mathrm{min})$ value of FGM samples is shown in table 4 which were measured from pin on disc type wear and friction monitor. 


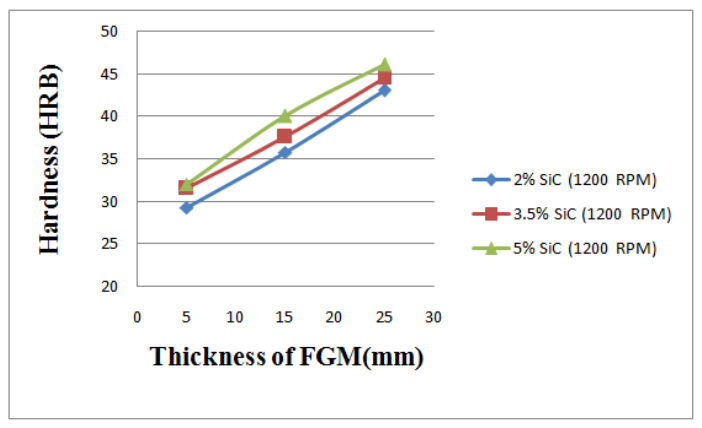

Figure 8: Variation of hardness with thickness of FGM sample and $w t \%$ of $\mathrm{SiC}$ particles at $1200 \mathrm{RPM}$

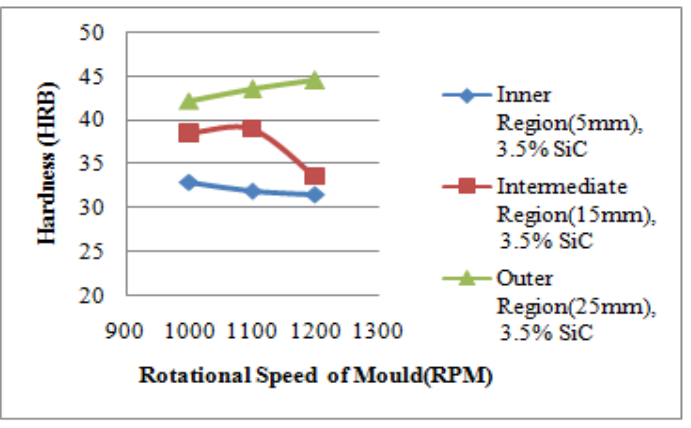

Figure 9: Variation of hardness with varying rotation speed of mould for $3.5 \%$ of $\mathrm{SiC}$ particles

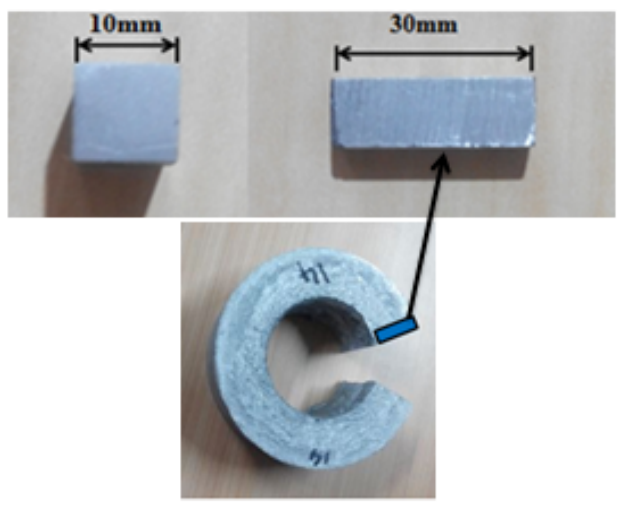

Figure 10: Wear sample

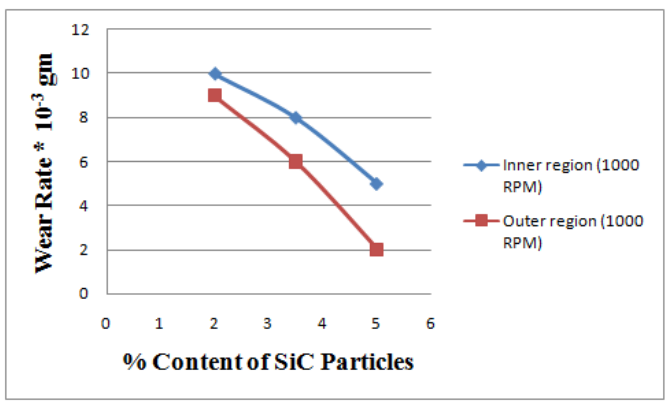

Figure11: Variation of wear rate with varying rotation speed of mould at matrix rich and particle rich region (For $2 \% \mathrm{SiC}$ ) 


\begin{tabular}{|c|c|c|}
\hline $\begin{array}{c}\text { Sample } \\
\text { Specification }\end{array}$ & $\begin{array}{c}\text { Material loss, } \\
\text { mg/min } \\
\text { (Inner surface) }\end{array}$ & $\begin{array}{c}\text { Material loss, } \\
\text { mg min } \\
\text { (Outer surface) }\end{array}$ \\
\hline $\begin{array}{c}1000 \mathrm{RPM} \\
2 \% \mathrm{SiC} \\
75 \text { micron }\end{array}$ & 0.01 & 0.009 \\
\hline $\begin{array}{c}1000 \mathrm{RPM} \\
3.5 \% \mathrm{SiC} \\
75 \mathrm{micron}\end{array}$ & 0.008 & 0.006 \\
\hline $\begin{array}{c}1000 \mathrm{RPM} \\
5 \% \mathrm{SiC}\end{array}$ & 0.005 & 0.002 \\
\hline $\begin{array}{c}75 \mathrm{micron} \\
1100 \mathrm{RPM} \\
2 \% \mathrm{SiC} \\
75 \mathrm{micron}\end{array}$ & 0.009 & 0.007 \\
\hline $\begin{array}{c}1200 \mathrm{RPM} \\
2 \% \mathrm{SiC}\end{array}$ & 0.006 & 0.004 \\
\hline $\begin{array}{c}75 \mathrm{micron} \\
1100 \mathrm{RPM} \\
2 \% \mathrm{SiC} \\
44 \mathrm{micron}\end{array}$ & 0.005 & 0.004 \\
\hline $\begin{array}{c}1100 \mathrm{RPM} \\
2 \% \mathrm{SiC} \\
6.5 \text { micron }\end{array}$ & 0.001 & 0.004 \\
\hline
\end{tabular}

Table 4: Wear rate (mg/min) of FGM samples

\subsection{Relationship of Hardness and Wear property with varying average grain size of the $\mathrm{SiC}$ particles}

To analyse the effect of particle grain size on hardness and wear property, two samples were made using $44 \& 6.5 \mu \mathrm{m}$ grain size $\mathrm{SiC}$ particles at $1200 \mathrm{RPM}$. Relationship of hardness property with varying average grain size $(75,44,6.5 \mu \mathrm{m})$ for $2 \% \mathrm{SiC}$ and mould speed of $1200 \mathrm{RPM}$ is shown in Figure 12. Hardness value is found more for FGMs having average grain size of 44 and $6 \mu \mathrm{m}$ compared to $75 \mu \mathrm{m}$ size $\mathrm{SiC}$ particles as smaller the grain size more number of particles per unit area. Thus, higher possibility to resist deformation. Due to having mixing problem for smaller size particles, hardness value for sample having $6.5 \mu \mathrm{m}$ size $\mathrm{SiC}$ particles shows lesser value compared to sample having 44 $\mu \mathrm{m}$ size $\mathrm{SiC}$ particles. Improper distribution of particles and cluster formation is the reason for decreased hardness of $6.5 \mu \mathrm{m}$ SiC FGM sample.

From Figure 13. it is seen that wear rate is less for FGM sample having 6.5 and 44 micron size $\mathrm{SiC}$ Particles than the FGM sample of SiC Particles of 75 micron size which contradict the fundamentals. As per fundamentals there is a weak interfacial strength between LM25 and SiC of smaller grain size because of smaller contact surface area $[9,10]$. There is not a significant difference in wear property for sample having 6.5 and $44 \mu \mathrm{m}$ size $\mathrm{SiC}$ particles at outer surface due to mixing problem and cluster formation. 


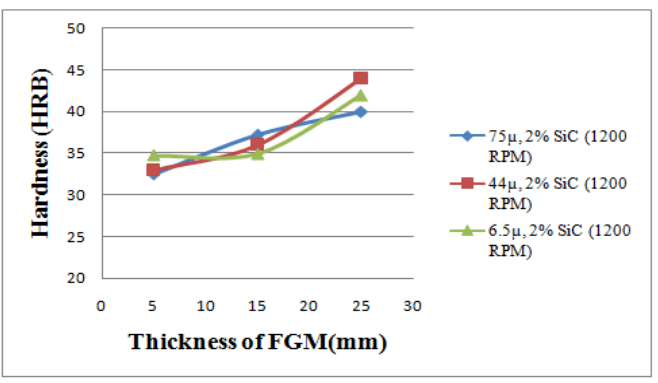

Figure 12: Variation of hardness with thickness of FGM sample and grain size variation of $\mathrm{SiC}$ particles

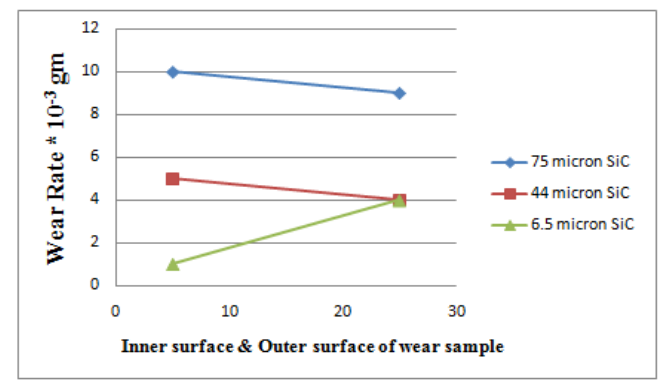

Figure 13: Variation of wear rate with varying $\mathrm{SiC}$ particle size $(75,44,6.5 \mu \mathrm{m})$ at inner and outer surface of wear sample

\section{Conclusion}

The main conclusions of this research work are:

- Total 9 FGM samples were successfully made by vertical centrifugal casting technique with varying mould rotation speed and $\mathrm{wt} \%$ of $\mathrm{SiC}$ particles. Another $2 \mathrm{FGM}$ samples were made by varying average grain size $(44,6.5 \mu \mathrm{m})$ of the $\mathrm{SiC}$ particles

- There is a considerable increase in hardness and wear resistance with increase in radial distance of FGM sample.

- Hardness value increases with decrease in average grain size of $\mathrm{SiC}$ particles ( 75 to 44 and 6.5 $\mu \mathrm{m})$ as higher number of particles per unit volume thereby higher possibility to resist deformation. Maximum hardness achieved for sample containing $5 \% \mathrm{SiC}$ of $75 \mu \mathrm{m}$ particle size with 1200 RPM was $46 \mathrm{HRB}$ at outer region [Table 3].

- FGM sample preparation at $1200 \mathrm{RPM}, 5 \% \mathrm{SiC}$ particles $(75 \mu \mathrm{m})$ gives the maximum increase of hardness (30HRB to $46 \mathrm{HRB}$ ), highest wear resistance property $(2 \mathrm{mg} / \mathrm{min})$ and gives better particle distribution in microstructure image [Table $3 \&$ Table 4].

- Wear resistant property increases with increase in mould rotation speed and $\mathrm{wt} \%$ of $\mathrm{SiC}$ particles [Figure 11].

- As per microstructure result, particle distribution was improved in FGM sample which were prepared at higher mould rotation speed (1200 RPM) due to larger centrifugal force [Figure 6]. Particles distribution was not good in FGM sample containing $6.5 \mu \mathrm{m}$ grain size $\mathrm{SiC}$ particles due to having mixing problem \& cluster formation.

\section{Reference}

[1] Niino M. , Hirai T. and Watanabe R. (1987), “The functionally gradient materials,” J Jap Soc Compos Mat, Vol.13, (pp. 257-264).

[2] Mahamood M., Akinlabi T. (2012) - "Functionally Graded Material: An Overview", Proceedings of the World Congress on Engineering, Vol 3. 
[3] Kumar S., Sharma R,, Mishra P.(2014) -“Functionally Graded Materials: A Critical Review”, International Journal of Scientific Footprints, Vol 2, (pp. 18-29).

[4] Rodriguez-Castro R., Wetherhold R. C. and Kelestemur M. H. (2002) - "Microstructure and mechanical behavior of functionally graded Al A359/SiCp composite," Materials Science and Engineering: A, Vol. 323, no. 1-2, (pp. 445-456).

[5] Watanabe Y., Kawamoto A., and Matsuda K. (2002) - "Particle size distributions in functionally graded materials fabricated by the centrifugal solidparticle method," Composites Science and Technology, vol. 62, no. 6, (pp. 881-888).

[6] Udapa G., Shrikantha S., and Gangadharan K.V.(2014) - "Functionally Graded Materials: An Overview", International conference on Advances in Manufacturing and Materials Engineering, AMME 2014, Procedia Materials Science, vol. 5, (pp. $1291-1299$ ).

[7] Abdulhaq A. , Mohammed M. (2014) - "A preparation and Characterization of Functionally Graded Aluminum Alloy Based Composite Via Casting Route" Al-Rafidain Engineering, vol.23 No. 1.

[8] Pai B., Pillai R.M., and Rajan T. (2010) - "Characterization of centrifugal cast functionally graded aluminum-silicon carbide metal matrix composites", Journal of Materials Characterization, vol. 61,( pp.923-928).

[9] Akhilesh J., Mahesh R. (2014) - "Property Analysis of Aluminium (LM-25) Metal Matrix Composite” International Journal of Emerging Technology and Advanced Engineering, vol. 4, Issue 2.

[10] Madhusudhan , Kumar M. , Narendranath S.(2013)- "Properties of Centrifugal Casting at Different Rotational Speeds of the Die" International Journal of Emerging Technology and Advanced Engineering, vol. 3, Issue .

[11] Jeong D.H., Gonzalez F., Palumbo G., Aust K.T. and Erb U. (2001) -“The effect of grain size on the wear properties of electrodeposited nanocrystalline nickel coatings”, Scripta Material, vol. 44, (pp. 493-499).

[12] Ahemad J., Bhaskar S.V., Kapgate R. A., D.Sadaphal N., and Kharde S. B. (2013) - "Development of Al/Sic5\%, Al/Sic10\%, $\mathrm{Al} / \mathrm{Sic} 15 \%$, Metal Matrix Composite And Its Comparision With Alumi-nium Alloy - LM25 On Tribological Parameters" , International Journal of Emerging Technology and Advanced Engineering, vol. 3, Issue 9,( pp.545-549).

[13] Ataiwi H., Atiyah A., and Madhloom A. (2014) - "Mechanical Characteristics of Prepared Functionally Graded Cylinder by Centrifugal Casting", Enggineering \& Technical Journal, vol.32, Part (A).

[14] Ferreira S.C., Velhinho A., Rocha L.A., and Braz Fernandes F.M.(2008) -"Microstructure Characterization of Aluminium Syntactic Functionally Graded Composites Containing Hollow Ceramic Microspheres Manufactured by Radial Centrifugal Casting”, Materials Science Forum vols. 587-588, ( pp. 207-211). 